\title{
The development of a self-evaluation checklist for measuring Filipino students' science giftedness
}

\author{
Aris Larroder ${ }^{1 *}$ and Masakata Ogawa ${ }^{2}$
}

\author{
* Correspondence: \\ alarroder@wvc.pshs.edu.ph \\ ${ }^{1}$ Philippine Science High School \\ Western Visayas Campus, Bito City, \\ Philippines \\ Full list of author information is \\ available at the end of the article
}

\begin{abstract}
Identification of science-gifted students remains a problem due to the lack of availability of a valid and reliable identification tool. There are several instruments published to identify science-gifted students in other countries, but it is difficult to assume the reliability and validity of these tools specifically for Filipinos' socially constructed notion of science giftedness. During initial stages of identification, some science-gifted students are excluded in nomination and selection because teachers are not particularly adept at evaluating the characteristics of these students. This paper reports the validity and reliability of an adapted 60-item checklist on science giftedness of Filipino students. The subjects for this study are 365 first-year high school students from various science-oriented secondary schools with different programs in the Philippines. The checklist was completed through self-rating. Exploratory factor analysis using the principal component analysis as the extraction method identified 12 factor components: scientific awareness, rational observation, experimentation, application, visualization, initiative, quantification, oblivion in learning, engrossment in learning, integrated learning, and acquiring of skills. Overall, results show that the Cronbach alpha reliability coefficient is 0.954 , which shows that the checklist is reliable in determining giftedness in the context of the Philippines. When students enrolled in four different science-gifted programs used this checklist to evaluate themselves there were significant differences in the range of scores. Further testing with an improved checklist using a wider demographic profile should be conducted. This study suggests that tools used to identify science giftedness must not only be domain specific, but should also be holistic and assess other facets of giftedness.
\end{abstract}

Keywords: Assessment, Factor analysis, High school students, Identification, Science giftedness

To access the executive summary of this paper in Tagalog, please check the supplemental materials associated with this article by clicking on this link (Additional file 1).

\section{Introduction}

Sociocultural conceptions of giftedness greatly affect gifted education around the world in terms of programs and services offered, program objectives, structure and organization, and community support (Clark 2000). The presence of gifted education in any country depends on whether it is embraced by national policy. In most cases, variations in implementation can be traced to the legislation a country has for its gifted

\section{Springer}

(c) 2015 Larroder and Ogawa. Open Access This article is distributed under the terms of the Creative Commons Attribution 4.0 International License (http://creativecommons.org/licenses/by/4.0/), which permits unrestricted use, distribution, and reproduction in any medium, provided you give appropriate credit to the original author(s) and the source, provide a link to the Creative Commons license, and indicate if changes were made. 
populace in general, and for its science-gifted citizens in particular. Even without any legal entitlements, some countries set up school environments for the science gifted within existing schools and in separately defined schools. Furthermore, the curriculum and instruction for the science gifted can be based on either a specialized administrative model (enrolling only science gifted students) or a general education model (offering differentiated instruction for all ability groups). Regardless of the model, identification and description of science gifted is limited and other measures should be considered (McGinnis and Kahn 2014).

Indeed, accurately identifying gifted students remains one of the major problems facing gifted education. The current identification process in the Philippines poses a major problem and has been described in a study by National Report on Identification: Assessment and Recommendation for Comprehensive Identification of Gifted and Talented Youth (Richert et al. 1982). The scarcity of identification of tools appropriate for identifying science-gifted students has allowed for the proliferation of exams that identify giftedness based on only a single type of intelligence or based on a single score on a cognitive ability exam. Ingham and Price (1993) argue that the practice of labeling Filipino students as science gifted should not be made on the basis of cognitive ability alone. Instead, there should be broader identification criteria and alternative identification procedures to help identify student's giftedness in science.

In the Philippines, there has been a prevalence of psychometric tests and nomination procedures used for placement purposes of various gifted populations in specialized schools such as science high schools. Despite the use of psychometric testing and educational assessment, these tools are found to be limited and restricting. Likewise, there exists a lack of congruence between the prevalent understanding of giftedness, which encompasses aptitude in various domains (Wong-Fernandez and Bustos-Orosa 2007), and diverse as well as broad measures of giftedness specific to the science domain. Nomination procedures, an initial step towards inclusivity, become problematic without a valid and reliable instrument to evaluate science giftedness among Filipinos. The problem of identification of gifted children is further aggravated by the high cost of standardized testing. Developing and standardizing a large-scale instrument requires a substantial amount of resources, so if these are not available the only recourse is the use of "borrowed" standardized tests. Vista and Grantham (2009) warned against the use of "borrowed" tests without checking the reliability and validity with the target population. Rating scales, along with other assessment forms, should play a role in giftedness identification if one views it as more than just a high IQ (Pfeiffer 2009). Furthermore, only a small number of teacher nomination instruments have been developed for rating the characteristics of high-ability students, and only a few studies have investigated the technical aspects of most scales (Renzulli 2009b). Sternberg (2007) argues that an identification scheme should reflect the cultural origins and context of the students and he also argues that educators and researchers need to adapt broader views and more culturally sensitive approaches for identifying giftedness in every culture and society. McGinnis and Kahn (2014) also suggest that other measures to describe science-gifted students should be considered and explored.

Currently, there are several instruments available to identify science-gifted students in other countries, but these tools have not been validated for use in the Filipino education system where the socially constructed notion of science giftedness may differ from 
the context in which the tools were originally developed. Therefore, there is a need for an identification tool to evaluate science giftedness among Filipino students. In this paper, we introduce an instrument that reflects a socially constructed notion of science giftedness that is grounded in Filipino cultural and social contexts. Specifically, this study aims to check the validity and reliability of Sumida's (2010) checklist in measuring the science giftedness of secondary Filipino students.

\section{Theoretical framework}

\section{Science giftedness from a sociocultural perspective}

Science giftedness is easier to interpret and identify than giftedness alone, due to "intuition." Intuition can be a process of arriving at an idea with a non-logical feeling for the significance of the idea and is a personal capability. Pupils who are science gifted are likely to: enjoy researching obscure facts and applying scientific theories, ideas, and models when explaining a range of phenomena; ask many questions, suggesting that they are willing to hypothesize and speculate; think logically, providing plausible explanations for phenomena; put forward objective arguments using combinations of evidence and creative ideas and question other people's conclusions (including their teachers'); and understand the concepts of reliability and validity when drawing conclusions from evidence (Gilbert and Newberry 2007). Several studies have been conducted on scientific giftedness, yet its definition and identification is a complex endeavor (Walters 2009). Phillipson (2007) believes that our conception of giftedness and perception of the traits of gifted behavior are driven by sociocultural perspectives. Furthermore, constructs of giftedness are uncovered through implicit theories, which involve asking what people think, a process referred to as "personal construction." WongFernandez and Bustos-Orosa (2007) report that identification through self-awareness and an assessment of one's abilities can also identify giftedness. As we try to explain the nature of giftedness, our personal construct of science giftedness is mediated by experience, language, and culture. In a highly diverse country like the Philippines that has been exposed to different cultures by its colonizers and has an archipelagic geography and a diversity of ethnolinguistic groups, the construct of science giftedness is probably defined by these factors through the members of its society.

\section{Identification of students for gifted programs}

Identification of students for gifted programs continues to be widely discussed and debated along with the definition of giftedness. Renzulli (2004) points out that how giftedness is defined or conceptualized should be the theoretical rationale underlying an identification system. The rationale must be the basis for how instruments are selected and used in identification. The problem with the current identification approach is its appearance of being multi-criteria when it is actually restrictive to a broader range of criteria. The approach fails to account for the society's diversity, and Baldwin (2004) calls for inclusivity of students from culturally diverse and under-served populations of gifted students. Innamorato (1998) advises the use of various identification tools to cover a wide range of abilities to characterize the science gifted, which he calls a "flexible model of assessment". Maker (2005) argued the need for an emerging paradigm that seeks to identify and conceive of giftedness as 
having multiple forms and she suggested the use of a field-oriented approach that is developmental in nature, process oriented, based on performance, and is collaborative at all levels. Sternberg (2007) advocates that we adapt a broader view and cultural approach of giftedness in every culture and society. In this study, we address primarily the diversity of gifted students in terms of school programs, and inclusivity in terms of gender and economic status. It is the aim of this paper to determine the Filipino constructs of science giftedness.

\section{Domain specificity of giftedness}

Where diversity and inclusivity are addressed in the identification process, it is also important to consider the domain specificity of giftedness. Innamorato (1998) reported that there are few attempts to develop a giftedness construct in the area of science, which reflects a consensus of the result of several investigations. Likewise, previous constructs of science giftedness are restricted to cognitive elements while non-cognitive elements are not included. This study addresses the gap due to the lack of non-cognitive elements to formulate the construct of science giftedness contextually and culturally. Despite the tension between domain generality and domain specificity in giftedness, Innamorato (1998) stresses the need for flexibility, inclusivity, and utility of holistic elements in an identification scheme for the science gifted. Han and Marvin (2002) investigated the tension between domain specificity and domain generality and suggested that we should recognize a person's creativity in specific domains. In giftedness studies, creativity and giftedness often are used interchangeably, which holds true in the context of this study. VanTasselBaska (2000) advocates the use of domain-specific checklist as one way of assessing behavior in context. The domain-specific approach allows the identification procedure to be distinct and includes broader range of talent areas especially in science, which is highly diverse field of study. In this study, we draw from Sumida's (2010) research in which he argued that some people show a bias toward a particular skill and strong aptitude in a specific field. To test this notion, Sumida developed a checklist to help identify science giftedness among Japanese students. This instrument was used because it is specific to science giftedness and because, the checklist was designed to characterize and classify different traits of science giftedness from an Eastern perspective.

\section{Research purpose}

The purpose of this study is to develop a checklist on science giftedness that could be used to evaluate science giftedness among Filipino students. We hope this checklist can be used to offer an emic perspective as to what Filipinos value as gifts in science. Likewise, the checklist may serve as rough guide for science teachers and educators to identify Filipinos' manifested behaviors in science. It also aims to find significant differences in the scores of students from various school programs. The aim is to be able to use these differences in science giftedness scores to help a variety of schools to address areas of science giftedness that need attention. We therefore asked the following questions: 
1. How effective is Sumida's (2010) checklist for determining science giftedness in Filipino students?

2. What are some limitations for using a tool developed in a different cultural context to identify science giftedness in the context of the Philippines?

3. What can Sumida's checklist (2010) reveal about the population of students who are currently receiving educational services in the four different governmentsupported programs examined in this research for gifted science education?

\section{Context for the study}

\section{Education for science-gifted students in the Philippines}

In this section, we provide some context for the way science gifted education is organized in the Philippines. Currently, in the Philippines, we utilize an integrated program and systems approach in the education of gifted students from elementary to tertiary levels. At the elementary level, gifted or talented children are placed in special classes with a special curriculum tagged as a Special Education (SPED) Program. These SPED programs, along with other science-oriented elementary schools, and elementary schools with special programs for science, all serve as "feeder" schools to provide students for gifted programs at the secondary level.

At the secondary level, gifted children are divided into two groups: 1) arts and 2) science and mathematics. Students who are gifted in the arts attend Philippine High School for the Arts (PHSA), while those who are gifted in science and mathematics attend either the Department of Science and Technology Science Education Institute's (DOST SEI) affiliated schools or the Department of Education's (DepEd) various science-oriented curricular programs. The DOST SEI sponsors the Philippine Science High School (PSHS). The DepEd has three major types of schools: Regional Science High Schools (RSHS), the Science and Technology (S\&T) oriented high schools and National High Schools with Special Science Programs (NHS-SSP). In regular schools, students who exhibit high aptitude in science and math may pursue science and math electives and other opportunities to nurture science giftedness. Figure 1 summarizes the different schools and educational programs science gifted students in the Philippines.

Figure 1 illustrates how elementary level schools and programs serve as "feeders" for the schools and programs at the secondary level. Students continue to tertiary level programs from those in the secondary level.

\section{Research setting}

In this study, we selected four different school programs from which to enroll student participants. The programs we examined are situated within two school sites Philippine Science High School (PSHS) and National High School with Special Science Program (NHS-SSP), each offering distinct educational programs designed to nurture different levels of science giftedness. PSHS had only one program for science gifted students, while NHS-SSP had three different programs (See Fig. 2). In the Philippines, the national policy ensures that secondary education is free and compulsory for all students. However, secondary schools have their own admission and retention policies.

For example, School Program 1 (SP1) is part of the PSHS for science-gifted students and students who pass a nationally administered exam can compete for admittance to 


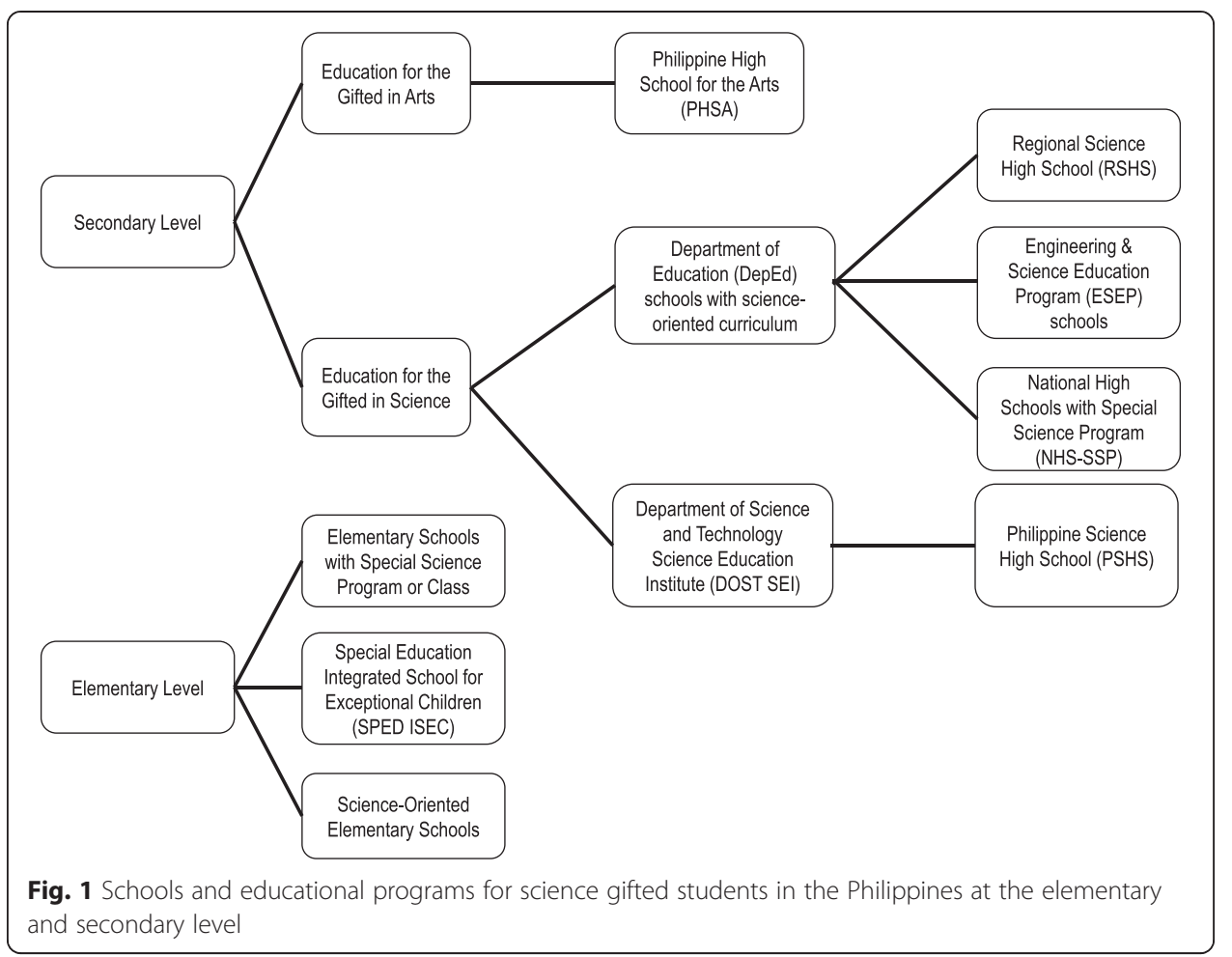

a limited number of spots in this program. Acceptance into SP1 entitles students to a scholarship that provides tuition, lodging, transportation, and a monthly stipend. Students selected for SP1 are required to major in science and engineering courses in college to prepare for advanced training in the fields of science and math. Admission to the each of the three programs (SP2, SP3, and SP4) in the NHS-SSP is also competitive, but admission to the actual school is restricted to students living within the region near the school. Tuition for the three programs in the NHS-SSP are free, but there are no provisions for a monthly stipend and lodging allowance like that offered in the program

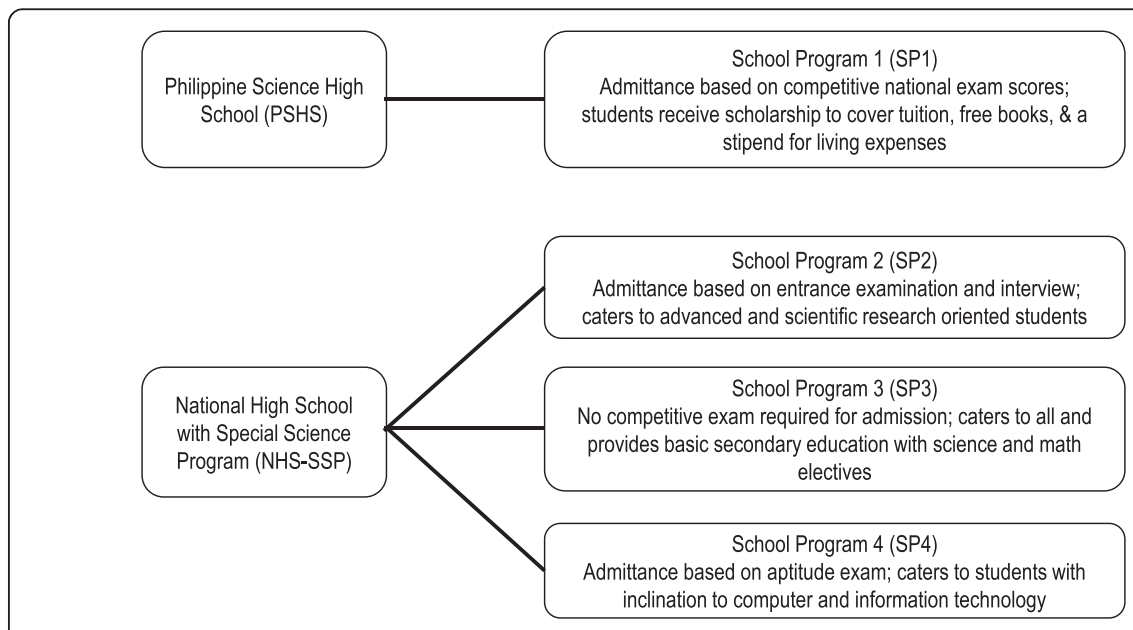

Fig. 2 Profile, admittance, and kind of students in each of the four different school programs 
at PSHS. Students admitted to SP1 are required to maintain a Grade Point Average (GPA) of 2.50 or higher in all subjects in order to retain their scholarship. Students who fail out of SP1 are allowed to transfer to other the other three programs at a NHS-SSP. Specifically, students who fail out of SP1 or another program can transfer to SP3, but it is more difficult for students to transfer to SP2 or SP4 because these programs have a limited number of vacancies to accommodate transferees.

Thus, all four programs have differences with regards to admission and retention policy. They also differ with regards to student-to-teacher ratio and funding. For example, PSHS receives the largest amount of funding, while the three programs in the NHS-SSP receive only moderate funding. In addition, SP1, SP2, and SP4 have a set student-teacher ratio (maximum of 1:30), but because SP3 cannot refuse any student - the student-teacher ratio in these classes can become quite large. Finally, the curriculum offered in all four programs is different. As mentioned previously, SP1 prepares students for tertiary level science and math education and is geared toward career preparation. SP2 caters to advanced and scientific research-oriented students. SP3 is a basic secondary education program, but also provides science and math electives for students with high interest and aptitude in these subjects. SP4 offers a curriculum for students who are inclined to computer and information technology.

Admission to these programs all require a pre-selection process, which includes high grades, especially in math and science, coupled with a recommendation from the school principal or science teacher via the nomination process. Some programs also include an interview as part of the screening process and others may include an entrance exam. However, a uniform and standardized nomination checklist is non-existent. Thus, a goal of our research is to develop a means for identifying students who may be talented in mathematics and science that is easy to implement and that could improve access and equity with regards to how students are chosen to participate in various programs and schools.

\section{Research participants}

The participants in this study were all enrolled in programs supported by the Gifted Children and Science-Oriented Youth Act (2007). The Act defines gifted Filipino children as those who have at least above-average general intellectual ability and who have demonstrated superior achievement and/or potential in any of the following areas: verbal or linguistic intelligence, logical or mathematical intelligence, body or kinesthetic intelligence, visual or spatial intelligence, musical or rhythmic intelligence, and leadership ability. The Act aims primarily to identify gifted Filipino children and scienceoriented youth at the earliest age possible. Based on School Year 2004-2005 estimates, there were 5.49 million Filipino children with special needs in the Philippines, or $13 \%$ of all children's population. Of this number, an estimated 4.2 million were persons with disabilities while 1.27 million were gifted children (Department of Education 2010).

Seventy-one students $(19.2 \%)$ were from a school catering to those with high aptitude in science and mathematics and the remaining 294 students (37.3 \%) were from a school with various special programs and with a special science curriculum. The ratio of total participants to items on Sumida's (2010) checklist (375:60) meets Nunnally and Bernstein's (Nunnally \& Bernstein 1994) minimum recommendation of 6:1. As a general guide, Tabachnick and Fidell (2012) suggest that in order to perform factor analysis, a sample 
size should be at least 300, with low communalities, a small number of factors, and 3 to 4 indicators for each factor. In this research, we followed our university guidelines for research involving minors/children so both parental consent and student assent were obtained for the three hundred and sixty-five students who volunteered to participate in the study.

\section{Instrument: Sumida's checklist}

The checklist on giftedness in science was developed originally by Sumida (2010) to identify gifted students among Japanese children, specifically in relation to science learning. We hope to use this checklist to identify which characteristics of science giftedness are demonstrated by Filipino students. The checklist consists of 15 items each on four strands (60 items total): attitudes, thinking, skills, and knowledge/understanding specific to science. The instrument employed a 5-point Likert-style questionnaire with the following scores: never -1 , occasionally -2 , seldom -3 , frequently -4 , and always -5 . It is available in Japanese and English and the published English version is used in this study. Using the instrument, students selected their answer from the Likert-scale options in the checklist to assess to what degree they agreed that they possessed the traits described in each item in the four strands in themselves. To ensure students' preferences for privacy and anonymity, writing their name on the checklist was optional. The English version of the checklist was adopted in this study and was evaluated by science teachers and educators from various school programs for content validity.

\section{Methodology and analytical procedure}

To improve upon the checklist by Sumida (2010), which consists of 60 items, and to deduce the latent science giftedness among Filipino students, factor analysis using the principal component analysis (PCA) extraction method was employed to reduce the number of items to identify factors of science giftedness specific to Filipino students. The objective of using PCA and of this study is to extract maximum variance from the data set, to reduce a large number of variables down to a smaller number of components, and to initiate factorial analysis to reveal the nature of component factors (Tabachnick \& Fidell 2012). Suitability of sample size, sample-to-variable ratio and Kaiser-Meyer-Olkin (KMO) Measure of Sampling Adequacy, and Bartlett's Test of Sphericity were determined prior to extraction of factors. Using Statistical Package for Social Sciences (SPSS) (version 17, released 2008) software, the $\mathrm{KMO}$ index was generated at 0.933 , where index value greater than 0.5 is considered suitable, while Bartlett's Test of Sphericity was generated at 0.000 which is statistically significant. Criteria for determining factor extraction were set using the cumulative percentage of variance and the eigenvalue greater than one rule. As the checklist consists of 60 items, the reliability and validity are affected due to the number of items to be assessed. In addition, we conducted ANOVA analysis to determine if there were any significant differences in students' self-reporting about giftedness using the Sumida checklist and their enrollment among the four different government-supported programs examined in this study. 


\section{Results}

\section{Descriptive analysis}

From 60 items, only 24 items were retained which is a result of the exploratory factorial analysis. The following section covers extensively the retention of these 24 items and the selection of two items in each of 12 factors. Table 1 (see below) presents the percentage of positive responses as 'frequent' and 'always' and the mean Likert scale score of items.

Table 1 Percentage of positive responses as frequently and always

\begin{tabular}{|c|c|c|c|}
\hline Factor & Items & $\begin{array}{l}\text { Percentage of positive } \\
\text { responses (frequently \& } \\
\text { always) }\end{array}$ & $\begin{array}{l}\text { Mean Likert } \\
\text { Scale Score }\end{array}$ \\
\hline \multirow[t]{2}{*}{$\begin{array}{l}\text { Factor } 1 \text { scientific } \\
\text { awareness }\end{array}$} & $\begin{array}{l}\text { Am I confident about my knowledge and } \\
\text { understanding of science? }\end{array}$ & 41.9 & 3.33 \\
\hline & $\begin{array}{l}\text { Do I understand quickly the content of science } \\
\text { classes? }\end{array}$ & 39.2 & 3.30 \\
\hline \multirow{2}{*}{$\begin{array}{l}\text { Factor } 2 \text { rational } \\
\text { observation. }\end{array}$} & Do I observe continuously over a long period? & 38.4 & 3.22 \\
\hline & $\begin{array}{l}\text { Do I find patterns in the results of an } \\
\text { observation and experiment? }\end{array}$ & 42.2 & 3.34 \\
\hline \multirow[t]{2}{*}{$\begin{array}{l}\text { Factor } 3 \\
\text { experimentation. }\end{array}$} & $\begin{array}{l}\text { Do I handle equipment used in an observation } \\
\text { and experiment correctly and adeptly? }\end{array}$ & 52.6 & 3.58 \\
\hline & $\begin{array}{l}\text { Do I take particular care when using equipment used } \\
\text { in an observation and experiment? }\end{array}$ & 63.9 & 3.88 \\
\hline \multirow{2}{*}{$\begin{array}{l}\text { Factor } 4 \text { concern } \\
\text { for nature. }\end{array}$} & Do I like to collect animals, plants, or rocks & 42.2 & 3.21 \\
\hline & Do I skillfully collect animals, plants or rocks? & 34.8 & 3.07 \\
\hline \multirow{2}{*}{$\begin{array}{l}\text { Factor } 5 \\
\text { application. }\end{array}$} & Do I show interest in making things? & 50.9 & 3.49 \\
\hline & $\begin{array}{l}\text { Do I attempt to apply things I have studied in } \\
\text { everyday life? }\end{array}$ & 59.1 & 3.65 \\
\hline \multirow[t]{2}{*}{$\begin{array}{l}\text { Factor } 6 \\
\text { visualization. }\end{array}$} & $\begin{array}{l}\text { Do I express my own ideas effectively in diagrams } \\
\text { and drawings? }\end{array}$ & 34.8 & 3.12 \\
\hline & $\begin{array}{l}\text { Do I draw accurate sketches of observations and } \\
\text { experiments? }\end{array}$ & 23.3 & 2.87 \\
\hline \multirow[t]{2}{*}{ Factor 7 initiative. } & $\begin{array}{l}\text { Do I dislike and get bored with easy repetitive } \\
\text { lessons or tasks? }\end{array}$ & 30.7 & 2.99 \\
\hline & $\begin{array}{l}\text { Do I try to do things in my own way, not by } \\
\text { the instruction? }\end{array}$ & 22.9 & 2.68 \\
\hline \multirow{2}{*}{$\begin{array}{l}\text { Factor } 8 \\
\text { quantification. }\end{array}$} & Do I show interest in analysis using numbers? & 35.9 & 3.12 \\
\hline & Do I like solving problems simply and efficiently? & 50.1 & 3.48 \\
\hline \multirow[t]{2}{*}{$\begin{array}{l}\text { Factor } 9 \text { oblivion } \\
\text { in learning. }\end{array}$} & $\begin{array}{l}\text { Do I carry out own observations or experiments } \\
\text { without concern for "success"? }\end{array}$ & 28.8 & 2.93 \\
\hline & $\begin{array}{l}\text { Do I have different ways of doing and thinking } \\
\text { from others without caring? }\end{array}$ & 20.0 & 2.70 \\
\hline \multirow{2}{*}{$\begin{array}{l}\text { Factor } 10 \\
\text { engrossment } \\
\text { in learning. }\end{array}$} & $\begin{array}{l}\text { Do I classify animals, plants or rocks by their } \\
\text { characteristics? }\end{array}$ & 47.9 & 3.65 \\
\hline & $\begin{array}{l}\text { Do I become too absorbed in an observation } \\
\text { and experiment to finish the task in time? }\end{array}$ & 39.5 & 3.28 \\
\hline \multirow{2}{*}{$\begin{array}{l}\text { Factor } 11 \\
\text { integrated } \\
\text { learning. }\end{array}$} & Do I prefer active learning to passive learning? & 54.6 & 3.64 \\
\hline & Do I grasp "the big picture" before the minutiae? & 29.8 & 3.13 \\
\hline \multirow{2}{*}{$\begin{array}{l}\text { Factor } 12 \\
\text { acquiring of skills. }\end{array}$} & Do I use computers adeptly or proficiently? & 64.3 & 3.84 \\
\hline & $\begin{array}{l}\text { Do I know the names of animals, plants, or rocks } \\
\text { in daily life? }\end{array}$ & 42.7 & 3.29 \\
\hline
\end{tabular}


Students use of the self-evaluation checklist showed that items in Factor 3 experimentation had two of the highest mean percentage of positive responses overall. Specifically, $63.9 \%$ indicated that they took particular care when using equipment in an observation or experiment (item 45) and $52.6 \%$ of students indicated they are adept at handling equipment when conducting experiments. Students also responded very positively to items in Factor 12 acquiring of skills, as $64.3 \%$ of students indicated they are adept and proficient at using computers (item 37). In addition Factor 5 application also showed high positive responses with $59.1 \%$ of students indicating they attempt to apply things they have studied in their everyday lives (item 10). These findings suggest that Filipino students who are gifted in science may have considerable exposure to laboratory equipment and to computers and that they feel capable of using these tools in learning.

Students reported low mean percentage of positive responses to several items. For example, only $20.0 \%$ of students responded positively when asked if the student engages in different ways of doing and thinking without concern for how others think (item 12) and only $28.8 \%$ responded positively when asked if the student carries out experiments without concern for success (item 44). Both of these items were in Factor 9 oblivion in learning, which suggests that Filipino students are mindful of how others might perceive their actions. Student responses to items in Factor 7 initiative confirm this assertion as only $22.9 \%$ of students indicated that try to do things in their own way without following instructions (item 14).

\section{Exploratory factor analysis on validity of items}

In our study, we recognize that Sumida's checklist may measure science giftedness among Japanese subjects, but may or may not measure science giftedness among Filipinos. Thus, we employed exploratory factor analysis to help measure the validity of which of these items could be applicable for determining science giftedness among Filipino students. The decision to conduct exploratory factor analysis is open to the discretion of the researcher's bias. For one, factor analysis has an array of rotations and extractions to choose from, given the same amount of variance from the original data. Therefore, there can be several ways solution can be interpreted which requires researcher's discretion on what has scientific utility. Naming the factors is also numerous and for this reason, exploratory factor analysis can be useful in helping researchers to determine the number of factors and to choose an extraction method and a rotation method whenever there are no hypotheses about the nature of the underlying factor structure.

After performing exploratory factor analysis and principal component analysis as extraction method, twelve component factors were generated (See Table 2). Factor loading values ranged from 0.43 to 0.69 , all of which exceed the threshold for adequate loadings (which is 0.30.)

Likewise, retention of 12 component factors was based on the Guttman-Kaiser rule stating that factors should have an eigenvalue larger than 1, which was true for all of these generated factors. While others favor the use of scree plot, Monte Carol test or others, to retain the number of factors, we choose to consider the Guttman-Kaiser rule due to very high and positive reliability of items (Cliff 1988). 
Table 2 Varimax-rotated principal components for students' responses to checklist items about self-perceived giftedness in science

\begin{tabular}{|c|c|c|c|c|c|c|c|c|c|c|c|c|}
\hline \multirow{2}{*}{$\begin{array}{l}\text { Checklist } \\
\text { item no. }\end{array}$} & \multicolumn{12}{|c|}{ Components } \\
\hline & 1 & 2 & 3 & 4 & 5 & 6 & 7 & 8 & 9 & 10 & 11 & 12 \\
\hline 57 & 0.70 & -0.08 & 0.20 & 0.08 & 0.19 & 0.04 & 0.09 & 0.19 & -0.10 & -0.07 & 0.01 & 0.08 \\
\hline 58 & 0.68 & 0.20 & 0.20 & 0.10 & 0.10 & 0.05 & 0.02 & 0.05 & 0.05 & -0.07 & 0.16 & -0.02 \\
\hline 6 & -0.03 & 0.61 & 0.04 & 0.26 & 0.17 & 0.13 & -0.17 & -0.03 & 0.17 & 0.10 & 0.14 & 0.06 \\
\hline 20 & 0.15 & 0.61 & 0.17 & 0.13 & 0.18 & 0.05 & 0.10 & 0.14 & -0.11 & 0.18 & 0.11 & -0.03 \\
\hline 32 & 0.17 & 0.19 & 0.68 & 0.03 & 0.12 & 0.10 & -0.13 & 0.06 & 0.05 & 0.19 & -0.08 & -0.11 \\
\hline 45 & 0.22 & 0.08 & 0.67 & 0.14 & 0.13 & 0.05 & -0.13 & 0.01 & -0.08 & 0.06 & 0.03 & -0.03 \\
\hline 8 & 0.11 & 0.15 & 0.00 & 0.74 & 0.15 & -0.02 & 0.07 & 0.11 & 0.04 & 0.07 & 0.10 & -0.02 \\
\hline 43 & 0.22 & 0.18 & 0.04 & 0.72 & -0.03 & 0.11 & -0.02 & 0.11 & 0.21 & 0.11 & -0.01 & 0.05 \\
\hline 9 & 0.17 & 0.20 & 0.14 & 0.28 & 0.59 & 0.07 & -0.03 & 0.15 & 0.15 & 0.11 & -0.02 & -0.01 \\
\hline 10 & 0.23 & 0.21 & 0.16 & 0.14 & 0.58 & 0.18 & 0.00 & 0.05 & 0.08 & 0.01 & -0.07 & 0.09 \\
\hline 39 & 0.15 & 0.16 & 0.13 & 0.09 & 0.11 & 0.73 & 0.01 & 0.11 & 0.07 & 0.08 & 0.22 & -0.01 \\
\hline 41 & 0.24 & 0.07 & 0.13 & 0.10 & 0.09 & 0.66 & 0.10 & 0.18 & 0.11 & 0.11 & -0.15 & 0.08 \\
\hline 28 & 0.06 & 0.15 & -0.02 & -0.09 & 0.03 & -0.12 & 0.71 & 0.04 & -0.02 & 0.04 & 0.01 & 0.22 \\
\hline 14 & 0.09 & 0.04 & -0.15 & 0.01 & 0.02 & 0.18 & 0.62 & 0.02 & 0.22 & -0.03 & -0.12 & -0.05 \\
\hline 3 & 0.07 & 0.18 & -0.01 & 0.05 & 0.05 & 0.26 & 0.06 & 0.62 & 0.15 & 0.07 & 0.04 & -0.05 \\
\hline 18 & 0.18 & 0.15 & 0.30 & 0.13 & 0.12 & 0.09 & 0.08 & 0.62 & -0.02 & 0.08 & 0.11 & 0.11 \\
\hline 44 & 0.18 & 0.02 & 0.06 & -0.01 & 0.02 & 0.00 & 0.06 & 0.03 & 0.78 & 0.15 & 0.03 & -0.02 \\
\hline 12 & -0.02 & 0.10 & -0.13 & 0.05 & 0.10 & 0.22 & 0.29 & 0.04 & 0.63 & -0.11 & -0.08 & 0.12 \\
\hline 30 & 0.19 & -0.01 & 0.19 & 0.29 & 0.04 & 0.18 & 0.08 & 0.12 & -0.02 & 0.59 & 0.14 & 0.13 \\
\hline 13 & 0.26 & 0.28 & 0.16 & -0.02 & 0.32 & -0.15 & 0.14 & 0.16 & 0.08 & 0.41 & 0.05 & -0.08 \\
\hline 60 & 0.33 & 0.05 & 0.09 & 0.03 & 0.10 & 0.08 & -0.10 & 0.10 & -0.03 & 0.10 & 0.68 & 0.08 \\
\hline 59 & 0.45 & 0.17 & 0.15 & 0.14 & -0.13 & 0.19 & 0.17 & 0.01 & 0.13 & -0.09 & 0.47 & 0.05 \\
\hline 37 & 0.10 & 0.14 & 0.38 & 0.24 & 0.31 & 0.03 & 0.00 & 0.03 & 0.02 & -0.14 & 0.18 & 0.41 \\
\hline 56 & 0.36 & 0.05 & -0.06 & 0.33 & -0.04 & 0.09 & -0.02 & 0.11 & 0.14 & 0.19 & 0.09 & 0.41 \\
\hline eigenvalue & 17.15 & 2.49 & 2.14 & 1.98 & 1.66 & 1.55 & 1.47 & 1.28 & 1.23 & 1.15 & 1.14 & 1.10 \\
\hline$\%$ variance & 28.59 & 4.14 & 3.57 & 3.30 & 2.76 & 2.60 & 2.45 & 2.14 & 2.04 & 1.92 & 1.90 & 1.80 \\
\hline $\begin{array}{l}\text { cumulative \% } \\
\text { variance }\end{array}$ & 28.59 & 32.73 & 36.30 & 39.61 & 42.37 & 44.96 & 47.41 & 49.55 & 51.59 & 53.51 & 55.41 & 57.16 \\
\hline
\end{tabular}

Note: Only loadings greater than 0.40 are given; eigen $>1.053 ; n=365$

Numbers in bold indicate major loadings for each item

Extraction method: Principal component analysis

Rotation methods: Varimax with Kaiser Normalization (KMO: 0.933)

In our study, only two items were included in each factor, however three items per factor is generally viewed as a minimum rather than an optimal number of items per scale. However, the high communality values in each item $(\geq 0.6-0.8)$ can be used to explain why the loaded 2 items in each factor fit in well in our 12 factor for gifted students' self-evaluation check list (Child 2006). Factors were further rotated using varimax rotation (orthogonal, or right angle) to produce a more parsimonious solution (Williams et al. 2010; Brown 2009). The choice of varimax over other rotations is for increased interpretability (Tabachnick \& Fidell 2012). For varimax, a simple solution means that each factor has a small number of large loadings and a large number of zero (or small) loadings. Results showed that there were 12 factors overall and two items were retained for each factor (see Table 3). 
Table 3 Interpretation of factors, including underlying unifying dimension or concept, and sample items

\begin{tabular}{|c|c|}
\hline Factor & $\begin{array}{l}\text { Interpretation of factors and underlying } \\
\text { dimensions }\end{array}$ \\
\hline $\begin{array}{l}\text { Factor } 1 \\
\text { scientific } \\
\text { awareness }\end{array}$ & $\begin{array}{l}\text { This factor measures knowledge, understanding, } \\
\text { and conceptions of the world, which can be } \\
\text { summed up This conveys that someone must } \\
\text { have an awareness of various phenomena taking } \\
\text { place around them and make connections or } \\
\text { associations with science. Awareness comes with } \\
\text { the confidence that a phenomenon can be } \\
\text { explained in a scientific way. The item with the } \\
\text { highest factor loading best supports this: "Am } \\
\text { I confident about my knowledge and } \\
\text { understanding of science?" }\end{array}$ \\
\hline $\begin{array}{l}\text { Factor } 2 \text { rational } \\
\text { observation. }\end{array}$ & $\begin{array}{l}\text { Science giftedness means persistence in } \\
\text { observing until connections, patterns, and } \\
\text { meaning can be attached to any event. } \\
\text { Investigation in various ways to find solutions } \\
\text { is conducted. }\end{array}$ \\
\hline $\begin{array}{l}\text { Factor } 3 \\
\text { experimentation. }\end{array}$ & $\begin{array}{l}\text { Inquiries are investigated by way of experiment. } \\
\text { Gifted children will always investigate; asking } \\
\text { questions is never enough for them, they prefer } \\
\text { to experiment. }\end{array}$ \\
\hline
\end{tabular}

Factor 4

concern

for nature.

Factor 5 application.

Factor 6 visualization

Factor 7 initiative.

Factor 8 quantification

Factor 9 oblivion in learning.

Factor 10 engrossment in learning.
Science-gifted children have the tendency to hoard objects, which interest them. Their interest leads them to collect objects such as animals, plants, or rocks so they can observe them more frequently.

Science-gifted individuals take an interest in the utility of information learned. Due to their innate ability to find connections among ideas, "what if's" of learned ideas are related to other areas.

Those gifted in science can make a concrete image of what they conceive. Any abstract idea has an imagery or representation. This is shown when metaphorical ideas and analogies come out of an abstract idea.

Learning is motivated by the interest to answer prevailing questions. Science-gifted individuals value learning, which has a direct bearing on current interest. If the information has no utility or cannot be connected to the present endeavor, it is dismissed. Often, the science gifted will attempt self-learning or find ways to get the information from others.

The science gifted view problems and solutions in terms of a numerical value. Ideas are represented in the form of numbers. They think in terms of numbers in an attempt to put values to any idea or concept.

Science-gifted children will learn and conduct science while being oblivious of people around them. They will learn science for learning's sake and find joy in learning.

Science-gifted children's attention is easily caught and once it is, there is a tendency to spend time engrossed in learning more about a particular interest. This leads to interests or hobbies pursued for a lifetime.
Example Items

Am I confident about my knowledge and understanding of science?

Do I understand quickly the content of science classes?

Do I observe continuously over a long period?

Do I find patterns in the results of an observation and experiment?

Do I handle equipment used in an observation and experiment correctly and adeptly?

Do I take particular care when using equipment used in an observation and experiment?

Do I like to collect animals, plants, or rocks

Do I skillfully collect animals, plants or rocks?

Do I show interest in making things?

Do I attempt to apply things I have studied in everyday life?

Do I express my own ideas effectively in diagrams and drawings?

Do I draw accurate sketches of observations and experiments?

Do I dislike and get bored with easy repetitive lessons or tasks

Do I try to do things in my own way, not by the instruction?

Do I show interest in analysis using numbers?

Do I like solving problems simply and efficiently?

Do I carry out own observations or experiments without concern for "success"?

Do I do different ways of doing and thinking from others without caring?

Do I classify animals, plants or rocks by their characteristics?

Do I become too absorbed in an observation and experiment to finish the task in time? 
Table 3 Interpretation of factors, including underlying unifying dimension or concept, and sample items (Continued)

\begin{tabular}{|c|c|c|}
\hline $\begin{array}{l}\text { Factor } 11 \\
\text { integrated } \\
\text { learning. }\end{array}$ & $\begin{array}{l}\text { Science-gifted children learn ideas not in } \\
\text { isolation but by seeing the entire picture } \\
\text { and connections among ideas. }\end{array}$ & $\begin{array}{l}\text { Do I prefer active learning to passive } \\
\text { learning? Do I grasp "the big picture" } \\
\text { before the minutiae? }\end{array}$ \\
\hline \multirow{2}{*}{$\begin{array}{l}\text { Factor } 12 \\
\text { acquiring } \\
\text { of skills. }\end{array}$} & \multirow{2}{*}{$\begin{array}{l}\text { Gifted children find ways to learn tools and skills. } \\
\text { Being very self-reliant and with a profound } \\
\text { interest, the science gifted attempt to acquire } \\
\text { skills related to the area of interest. }\end{array}$} & $\begin{array}{l}\text { Do I use computers adeptly or } \\
\text { proficiently? }\end{array}$ \\
\hline & & $\begin{array}{l}\text { Do I know the names of animals, plants, } \\
\text { or rocks in daily life? }\end{array}$ \\
\hline
\end{tabular}

Reliability of the science-giftedness checklist

Sumida's (Sumida 2010) Gifted Behavior Checklist in Science for Primary Children is highly reliable and valid for Filipino students. A value of 0.954 Cronbach's Alpha was generated after performing the reliability test analysis. Cronbach's Alpha values or item scale ranged from 0.952 to 0.954 in all items. This is corroborated by a study of Nunnally and Bernstein (1994) that suggests that the minimum level of alpha coefficient is 0.70 for a good test.

\section{Factor interpretation}

Interpretation of factors involves understanding the underlying dimension or concept that unifies the group of variables loading on it (Tabachnick and Fidell 2012). Only items with factor loadings greater $>0.40$ as the minimum criterion for loading were retained. A factor loading is significant when loadings value is 0.30 or higher with a sample of 100 and it becomes more salient when there are more participants (Brown 2009). For factors with more than two items, the first two items of highest loading factors were chosen consistently and were deemed significant items.

In summary, the twelve factors include scientific awareness, rational observation, experimentation, application, visualization, initiative, quantification, oblivion in learning, engrossment in learning, integrated learning, and acquiring of skills.

\section{Analysis of variance}

Based on the results of factor analysis, there is a basis for all items in each factor to be added to generate a single score for all twelve factors. In this test, however, only the first two high-factor loading values were added to generate the mean and represent as a single score. Tabachnick and Fidell (2012) suggest that, as a rule of thumb, only loadings higher than 0.32 should be interpreted. However, the greater the factor loading value, the more the variable is a pure measure of a factor. For as long as the factor loading value meets the minimum factor loading of 0.32 , the choice of the cut-off for size of the loading is within the researcher's discretion. Likewise, Comrey and Lee (1992, in Tabachnick and Fidell 2012) advise choosing higher factor loadings because this leads to a higher percentage of overlapping variance and these are considered excellent test items. In our research, we considered that readers who impose their own perspectives and cultural bias might misinterpret the interpretation of interrelatedness of items based on factor loadings. This is because the underlying dimension that unifies all variables in a factor is open to varied interpretation. Likewise, the researcher has to strike a balance on the number of factors to be included. Thus, what constitutes too 
few factors for some studies may be too many for others, depending on how many the needs of the researcher.

The means of all scores were used to investigate the significant difference in the science-giftedness scores of various school programs, which cater to science giftedness. Furthermore, the reduced number of items from 60 to 24 leads to an improved checklist on science giftedness among Filipinos. Figure 3 and Table 4 below show the differences among means and the analysis of variance (ANOVA). ANOVA was performed to determine if indeed the means of pairs in twelve factors as dependent variables are statistically significant set at p-value greater than 0.01 or 0.05 , respectively when school programs as the independent variable.

Factors that were found statistically significant were further subjected to post hoc analysis using Scheffe's test for equality of variances. In SPSS (SPSS, Inc. 2007), Scheffe's test performs simultaneous joint pair-wise comparisons for all possible pairwise combinations of means (see Table 4).

A significant difference in science-giftedness scores was found on the following factors: scientific awareness $(\mathrm{F}=2.993, p=0.031)$, experimentation $(\mathrm{F}=2.733, p=0.044)$, initiative $(\mathrm{F}=4.423, p=0.005)$, oblivion in learning ( $\mathrm{F}=3.834, p=0.010)$, engrossment in learning ( $\mathrm{F}=7.246, p=0.000)$, and acquiring of skills $(\mathrm{F}=5.387, p=0.001)$, while there is no significant difference to other remaining factors. For the experimentation factor, significant difference was observed as a whole but Sheffe's test did not provide any significant difference among the four programs. In the factor of scientific awareness, SP3 showed higher scores than SP4. The initiative and oblivion in learning factors shows that SP1 outperformed SP3 and SP4. We also found that SP3 had the highest scores when compared with SP1 and SP2 in the engrossment in learning factor. Finally, SP3 had higher scores than SP1 in the acquiring of skills factor. In the rest of the factors rational observation, concern for nature, application, visualization, quantification, and integrated learning, all school programs achieved comparable scores.

In the result of ANOVA, the researchers cannot do otherwise to interpret the significant differences among factors of science giftedness. The lack of opportunity to observe

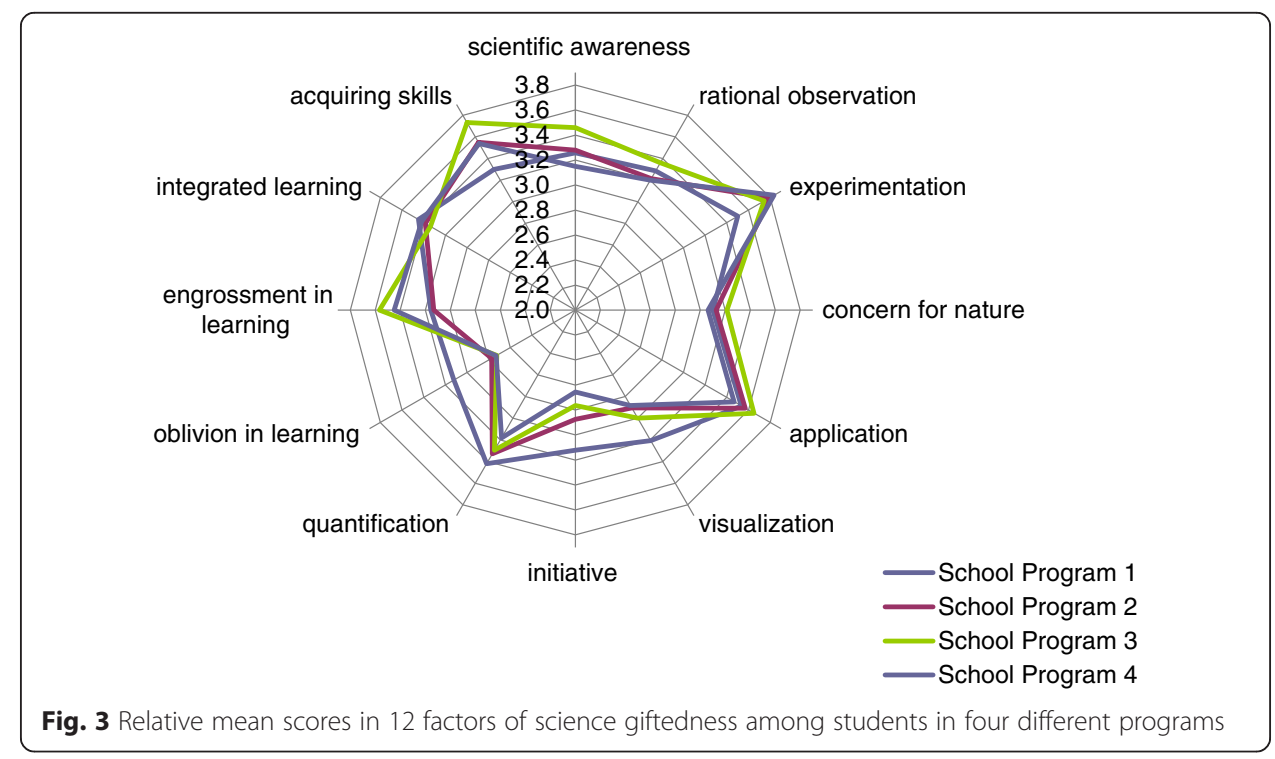


Table 4 One-way ANOVA of significant differences in mean scores of 12 factors of science giftedness among students in four different school programs

\begin{tabular}{|c|c|c|c|c|c|}
\hline \multirow{2}{*}{$\begin{array}{l}\text { Factors of Science } \\
\text { Giftedness }\end{array}$} & \multirow[t]{2}{*}{$F$ value } & \multicolumn{4}{|c|}{ Mean (SD) of the four different school programs (SPs) } \\
\hline & & SP1 & SP2 & SP3 & SP4 \\
\hline 1 Scientific awareness & $2.993^{*}$ & $3.26(0.70)$ & $3.28(0.87)$ & $3.46^{\mathrm{a}}(0.76)$ & $3.15^{\mathrm{b}}(0.76)$ \\
\hline 2 Rational observation & 0.939 & $3.29(0.77)$ & $3.22(0.76)$ & $3.36(0.80)$ & $3.20(0.79)$ \\
\hline 3 Experimentation & $2.733^{*}$ & $3.50(0.75)$ & $3.80(0.81)$ & $3.75(0.83)$ & $3.84(0.70)$ \\
\hline 4 Concern for nature & 0.418 & $3.10(0.90)$ & $3.13(1.00)$ & $3.21(1.02)$ & $3.06(1.19)$ \\
\hline 5 Application & 0.789 & $3.54(0.79)$ & $3.57(0.93)$ & $3.65(0.90)$ & $3.47(0.82)$ \\
\hline 6 Visualization & 2.144 & $3.21(0.87)$ & $2.91(0.85)$ & $3.00(0.87)$ & $2.88(0.88)$ \\
\hline 7 Initiative & $4.423^{* *}$ & $3.12^{b}(0.66)$ & $2.87^{\mathrm{ab}}(0.83)$ & $2.76^{\mathrm{a}}(0.91)$ & $2.66^{c}(0.81)$ \\
\hline 8 Quantification & 1.028 & $3.42(0.87)$ & $3.33(0.87)$ & $3.29(0.79)$ & $3.18(0.92)$ \\
\hline 9 Oblivion in learning & $3.834^{* *}$ & $3.12^{\mathrm{b}}(0.67)$ & $2.77^{\mathrm{ab}}(0.77)$ & $2.72^{\mathrm{a}}(0.96)$ & $2.73^{\mathrm{a}}(0.89)$ \\
\hline 10 Engrossment in learning & $7.246^{* *}$ & $3.16^{\mathrm{b}}(0.82)$ & $3.13^{\mathrm{a}}(0.77)$ & $3.57^{b}(0.78)$ & $3.45^{\mathrm{ab}}(0.78)$ \\
\hline 11 Integrated learning & 0.394 & $3.45(0.80)$ & $3.39(0.80)$ & $3.34(0.71)$ & $3.42(0.75)$ \\
\hline 12 Acquiring of skills & $5.387^{* *}$ & $3.30^{\mathrm{a}}(0.73)$ & $3.55^{\mathrm{ab}}(0.70)$ & $3.73^{b}(0.73)$ & $3.54^{\mathrm{ab}}(0.78)$ \\
\hline
\end{tabular}

the respondent for an ample time prevents us from making sense of the significant difference. We cannot interpret why students in a certain school programs manifest significantly in factors, such as, initiative and acquiring skills.

\section{Discussion}

This study aimed to develop a checklist on science giftedness that could evaluate giftedness in science among Filipino students and to validate if this checklist could be used to nominate Filipino students for programs designed to support students who are gifted in science. From our data, we seek to identify the salient characteristics of Filipinos who are gifted in science and to identify limitations when using a tool that was developed in a different cultural context. We also sought to find the significant differences in the science-giftedness scores of students from various school programs. Overall, our findings suggest that the reduced number of items in the checklist provides a glimpse of how science giftedness is demonstrated and manifested in Filipino students. In this section, we expand on findings related to each of these research goals.

\section{Effectiveness of using Sumida's checklist to evaluate science giftedness among Filipino students}

Our data suggests that our checklist on science giftedness is highly valid and reliable in measuring the science giftedness of Filipino students. Specifically, the checklist measured 12 factors, or dimensions, of science giftedness among Filipino students, and found the most salient factor to be scientific awareness. These findings would suggest that scientific awareness, by means of knowing and understanding a phenomenon as it unfolds, is a key characteristic of a science-gifted Filipino student. Because scientific awareness becomes formalized or concretized when an event or phenomenon arouses the interest and curiosity of the child, science-gifted individuals should be supported to actively pursue their own learning and find meaning by observing or conducting an 
inquiry. As they have a greater ability to see the connection and utility of learning with regard to a certain phenomenon, they may also become deeply engrossed in learning about a topic in depth, without losing the big picture and while also seeing the interrelationships of other ideas to any topic of interest.

The identification of those gifted in science, therefore, goes beyond recognizing an aptitude for knowing and understanding science. Researchers also need to be able to measure how scientific awareness becomes a tool in finding connections, making meaning, providing utility, and formalizing these ideas in concrete terms. It is important that one has a high degree of knowledge, but more important is how that knowledge is used. In today's world where information abounds, there is a need to make sense of the enormous amount of information and find utility in it. These findings have some important implications for teachers. For example, if a student is interested in information related to science, they can learn tremendously of their own desire. Science teachers should ensure that they provide students an opportunity to demonstrate the character trait of scientific awareness in the classroom by designing activities that encourage and develop this trait. Teachers can support science-gifted students to find information related to their interests and they can encourage self-guided inquiry to foster other characteristics of science-gifted students.

\section{Understanding Filipino students' science giftedness in context}

Based on our findings, Filipino students' science giftedness is characterized by rational observation, initiative, and integrated learning. These findings are similar to other studies (Innamorato 1998) showing that science gifted students tend to possess analogical reasoning, independence, and have the ability to shift thinking across cognitive domains. An early study (Fleigler, 1961, as cited in Walters 2009) using a checklist of science domain-specific characteristics found these gifted individuals share similar traits to those in our study, including early interest in science, early ability to understand abstract concepts, love of collecting natural objects, creativity in science projects and assimilate marginally related ideas. These traits are comparable to engrossment in learning, visualization, concern for nature, experimentation and integrated learning in our study. These findings indicate that Filipinos' science-giftedness traits do not necessarily differ from other cultural groups in terms of initiative and love of learning.

However, there are some interesting differences. Our results show that among the 60 items analyzed, item \#14 "Do I try to do things in my own way, not by instruction," recorded the lowest mean. This can be attributed to the cultural expectation that Filipino students should abide by instructions from people of authority, such as a teacher or other adults. Filipino children are often told by their teachers to wait for their instruction. For example, the term 'instruction' is prevalent in any class activity, but especially when students are asked to take an exam where one has "follow instructions". Failure to follow instruction would be considered defiance to authority and, in this case, defying the teacher. As such, an item like this may be less indicative of creativity or giftedness than it is an indication of how strongly a child adheres to cultural norms about how to be a "good student". Filipino students would likely perform poorly on other items, such as, \#12 "Do I act and think differently to others without caring", \#29 Do I ask the teacher unanticipated questions, and \#2 Do I like to investigate natural phenomena of my own accord. A student 
may be reluctant to rate themselves highly on these items as they represent behaving in ways that may disturb the social harmony and which could result in being labeled as deviant. In Filipino culture, if a student did something differently from others, it would be an indication that the student does not value conformity and may be willing to challenge authority.

Ingham and Price (1993) note that Filipinos' cultural orientation is deeply embedded in the assumption of authority by teachers in school. In their study of Filipino adolescents, greater preference was shown to authority figures, like parents and older family members, which is consistent with the value system of the culture. In addition, in the science domain of creative performances, Ingham and Price (1993) found out that science-gifted adolescent Filipinos prefer to learn through their tactile (hands-on) sense, contrary to the findings of this study in which students have a tendency to visualize their learning. This difference could be attributed to the impact of technological developments in the twenty years since that study was conducted. Additional research needs to be conducted that includes a wider geographical area that encompasses more schools and programs that are more representative of the diversity of cultures in Filipino society. Additionally, cross-country comparative studies could be helpful in developing a wider range of constructs of science giftedness in different cultural contexts.

\section{Effectiveness of tool for measuring differences among students in different programs}

The checklist was proven effective as a tool to measure the differences on science giftedness among students in different school programs. Results show that significant differences exist among school programs in six out of the twelve factors of science giftedness. These factors are aspects of scientific awareness, experimentation, initiative, oblivion in learning, engrossment in learning, and acquiring of skills. If these factors are manifestations of science giftedness as revealed by factor analysis, students must demonstrate these qualities or factors of science giftedness. Among school programs, SP3 and SP4 were found to have significant differences in three factors (scientific awareness, initiative, and oblivion in learning). We also found SP1 and SP3 have significant differences in four factors (initiative, oblivion in learning, engrossment in learning, and acquiring of skills). Finally, the engrossment in learning factor shows significant differences between SP2 and SP3, and SP1 and SP2.

Our analysis revealed that students in each program did not significantly differ from one another regarding their abilities on factors in rational observation, concern for nature, application, visualization, quantification, and integrated learning. The results reveal that school programs do not differ on how these abilities are nurtured despite the differences in the curriculum. However, these findings also suggest that the four school programs may be able to promote different factors among Filipino students to enhance science giftedness.

Our findings reveal that the checklist adapted from other culture and another context must be validated for one's own defined purpose. The similarity of measure on science giftedness does not guarantee that all items are valid and reliable. The factors of science giftedness differ from the context of Japan and the Philippines. The findings also reveal that differences exist among abilities of students on factors of science giftedness. It can 
be surmised that educational services differ as to how science giftedness is nurtured or promoted among students in various school programs. This finding is important because it raises some important questions about how gifted students are identified based solely on examinations for admittance in school programs, the absence of checklist to nominate or to identify science gifted, and the failure of educational service to nurture and promote the factors of science giftedness.

\section{Implications}

In this section, we conclude by discussing the implications of our findings for educators who are tasked with identifying which students may exhibit talents in math and science that could be developed. We believe our findings reveal that the current process for identifying students for enrollment in special science programs could be more effective. Currently, the identification of Filipino students who are gifted in science (as well as mathematics) involves a two-stage process: nominations and screening. Nomination is a crucial step by which a child is chosen to take the screening process. In the Philippines, where humility is more valued than self-promotion, it is unlikely that a nomination would come from parents, family members, or self-nomination.

While we have found some instances where students who do not belong to the top $10 \%$ for achievement have been nominated for the screening process, it is rare for this to happen in subject areas like math and science (Larroder and Ogawa 2013). As a result, the decision to nominate a student is generally reliant on teachers. There can be considerable bias at this crucial stage unless the teachers or any nominators are well trained in both gifted and talented identification strategies and multicultural education (Bernal 2009) and in the nature of science giftedness in particular. However, teachers generally use nomination forms and rating scales that have been developed within the school or region and that are not valid or reliable instruments. The lack of scientific rigor in the nomination process can have a profound impact on the overall reliability of the nomination process (Pfeiffer and Blei 2008). Researchers (Fraiser, 1991, as cited in Valdés 2003) warn that reliance on teacher nominations could contribute to the exclusion of some deserving students due to teacher bias. Because teachers' decisions are often influenced by a students' academic performance in math and science, students who may perform poorly on exams, but who have an aptitude for science and mathematics could be excluded from the screening process.

While it is unknown how many deserving children have been overlooked due to a teacher's personal bias, Feldhusen and Jarwan (2000) noted that identification systems that fail to assess students' abilities and talents in multiple ways should be used with extreme caution (Feldhusen and Jarwan 2000). For these reasons, nominations should not focus exclusively on intellectual ability or giftedness, but should also cover a wide array of specific abilities and talents. Renzulli (Renzulli 2009a) even suggests that selfnomination may be more appropriate for students who are considering advanced classes at the secondary level. However this can also be problematic as Gagne (1993, in Feldhusen and Jarwan 2000) found considerable differences in teachers' and students' peer nominations regarding the incidence of male and female students who were identified as being talented in the areas of creativity, cognitive abilities, socio-affective activity, physical prowess, academic talent, technical skills, artistic talent, and interpersonal 
functioning. This suggests that factors, such as gender, can impact how teachers and students view the talents of other students relative to how they view themselves.

For these reasons, we suggest that the nomination process for identifying students who are talented in math and science need to be revised to include more methods for nominating students for the screening process. Our findings suggest the revised checklist we developed has some value for supporting teachers and parents to evaluate more than a students' academic achievement. We also believe that when developing checklists, they should contain contradictory characteristics (Smith and Campbell 2012) that help researchers detect bias related to perceptions of intelligence or ability. However, we believe that more research needs to be done to develop an instrument that is appropriate for the Philippine educational context as many of the items in Sumida's original checklist may not be compatible with Filipino cultural norms.

Teachers, researchers, and policy makers should work together in the identification of the science gifted. Teachers should provide educational programs and services to promote science giftedness. The science curriculum in particular should cater to the needs of the science gifted so that factors of science giftedness can be displayed. The researchers can look into other dimensions of science giftedness, which are not included in the checklist used. There might be other aspects of science giftedness waiting to be uncovered. Researchers might want to consider the indigenous conceptions of giftedness. Finally, policy makers need to design programs to enhance the factors of science giftedness and the country needs policies to help all stakeholders (parents, teachers, and educators) to identify the latent characteristics of science giftedness in the populace.

\section{Additional file}

Additional file 1: Executive summary. (PDF $97 \mathrm{~kb})$

\section{About the Authors}

1 Aris Larroder is a public secondary school teacher for science-gifted students in the Philippines. He graduated with his PhD in Science Education from Tokyo University of Science. Dr. Larroder's research focuses on understanding the nature of science giftedness from a sociological perspective.

2 Masakata Ogawa is Professor of Science Education in the Graduate School of Mathematics and Science Education at Tokyo University of Science. After getting his Doctorate in plant physiology at Kyoto University, he taught science education courses at Ibaraki University, Hiroshima University and Kobe University. His research interests include cultural aspects in science education (especially in East-Asian regions), science education policy, and science teacher education.

\section{Author details}

${ }^{1}$ Philippine Science High School Western Visayas Campus, Bito City, Philippines. ${ }^{2}$ Graduate School of Mathematics and Science Education, Tokyo University of Science, Tokyo, Japan.

Received: 21 September 2015 Accepted: 13 November 2015

Published online: 21 December 2015

\section{References}

Baldwin, A. (2004). Culturally diverse and underserved populations of gifted students. In S. Reis (Ed.), Essential readings in gifted education (pp. 1-191). Thousand Oaks: Corwin Press and National Association for Gifted Children.

Bernal, E. (2009). Multicultural assessment. In B. Kerr (Ed.), Encyclopedia of giftedness, creativity, and talent (pp. 594-597). Thousand Oaks: Sage Publications.

Brown, J. D. (2009). Choosing the right type of rotation in PCA and EFA. Shiken: JALT Testing \& Evaluation SIG Newsletter, 13(3), 20-25.

Child, D. (2006). Essentials of factor analysis (3rd ed.). NY: Continuum.

Clark, B. (2003). Worldwide Survey 2000: Cross-cultural identification of gifted students. Reported in World Gifted. The Newsletter of the World Council for Gifted and Talented Children (WCGTC). Website online at http://www. worldgifted.org

Cliff, N. (1988). The eigenvalues-greater-than-one rule and the reliability of components. Psychol Bull, 103, 276-279. 
Department of Education. (2010). DepEd pushes for creation of Bureau of Special Education Retrieved from http:// www.rexpublishing.com.ph/news/news.php?nid=21

Feldhusen, J., \& Jarwan, F. (2000). Identification of gifted and talented youth for educational programs. In K. A. Heller, F. J. Mönks, R. F. Subotnik, \& R. J. Sternberg (Eds.), The International Handbook of Giftedness and Talent (2nd ed., pp. 271-282). Oxford: Elsevier Science.

Gifted Children and Science-Oriented Youth Act of 2007, S. 1534, 14 ${ }^{\text {th }}$ Cong. (2007).

Gilbert, J., \& Newberry, M. (2007). The characteristics of the gifted and exceptionally able in science. In K. Taber (Ed.), Science education for the gifted learners (pp. 15-31). New York: Routledge.

Han K, Marvin C. (2002). Multiple creativities? Investigating domain-specificity of creativity in young children. Special Education and Communication Disorders Faculty Publications. Paper 90. http://digotalcommons.unl.edu/ specedfacpub/90

Ingham, J., \& Price, G. (1993). The learning styles of gifted adolescents in the Philippines. In R. Milgram, R. Dunn, \& G. Price (Eds.), Teaching and counseling gifted and talented adolescents: An international learning style perspective (pp. 149-159). Westport: Praeger.

Innamorato, G. (1998). Creativity in the development of scientific giftedness: Educational implications. Roeper Rev, 21(1), 54-59.

Larroder, A., \& Ogawa, M. (2013). Nature and extent of science giftedness education in the Philippines via Philippines Science High School. Paper presented at the Fifth International Conference on Science and Mathematics Education of the SEAMEO Regional Centre for Science and Mathematics, November 11-14, Penang, Malaysia.

Maker CJ. (2005). The DISCOVER Project: Improving assessment and curriculum for diverse gifted learners. The National Research Center on the Gifted and Talented. Retrieved on line from http://www.gifted.uconn.edu/nrcgt/newsletter/ fall05/fall053.html

McGinnis, J. R., \& Kahn, S. (2014). Special needs and talents in science learning. In N. Lederman \& S. Abell (Eds.), Handbook of research on science education (Vol. 2, pp. 223-245). New York: Taylor \& Francis.

Nunnally, J. C., \& Bernstein, I. H. (1994). Psychometric theory (3rd ed.). New York: McGraw-Hill.

Pfeiffer, S. (2009). Gifted rating scales. In B. Kerr (Ed.), Encyclopedia of giftedness, creativity, and talent (pp. 390-392). Thousand Oaks: Sage Publishing.

Pfeiffer, S., \& Blei, S. (2008). Gifted identification beyond the IQ test: Rating scales \& other assessment procedures. In S. Pfeiffer (Ed.), Handbook of giftedness in children: psycho-educational theory, research and best practices (pp. 177-198). New York: Springer Science + Business Media.

Phillipson, S. (2007). A framework for the study of sociocultural perspectives of giftedness. In S. N. Phillipson \& M. McCann (Eds.), Conceptions of giftedness: Sociocultural perspectives (pp. 1-34). Mahwah: Lawrence Erlbaum Associates.

Renzulli, J. (2004). Identification of students for gifted and talented programs. In S. Reis (Ed.), Essential readings in gifted education (pp. 1-137). Thousand Oaks: Corwin Press and National Association for Gifted Children.

Renzulli, J. (2009a). Revolving door identification model. In B. Kerr (Ed.), Encyclopedia of giftedness, creativity, and talent (pp. 736-740). Thousand Oaks: Sage Publishing.

Renzulli, J. (2009b). Teacher nomination. In B. Kerr (Ed.), Encyclopedia of giftedness, creativity, and talent (pp. 878-880). Thousand Oaks: Sage Publishing.

Richert, E. S., Alvino, J., \& McDonnel, R. (1982). National report on identification: assessment and recommendations for comprehensive identification of gifted and talented youth. Sewell.: Educational Improvement Center.

Smith, L. M., \& Campbell, J. (2012). The social construction of giftedness. In Families, education and giftedness: Case studies in the construction of high achievement (pp. 1-22). Rotterdam: Sense Publishers.

SPSS, Inc. (2007). SPSS Base 17.0 user's guide. Chicago: SPSS.

Sternberg, R. J. (2007). Why a cultural approach to giftedness? In S. N. Phillipson \& M. McCann (Eds.), Conceptions of giftedness: Socio-cultural perspectives (pp. 15-18). Mahwah: Lawrence Erlbaum Associates.

Sumida, M. (2010). Identifying twice-exceptional children and three gifted styles in the Japanese primary science classroom. Int J Sci Educ, 32(15), 2097-2111.

Tabachnick, B. G., \& Fidell, L. (2012). Using multivariate statistics (6th ed.). Upper Saddle River: Pearson Education

Valdés, G. (2003). In search of giftedness: The case of Latino immigrant children. In Expanding definitions of giftedness: The case of young interpreters from immigrant communities (pp. 1-24). Mahwah: Lawrence Erlbaum Associates.

VanTassel-Baska, J. (2000). The on-going dilemma of effective identification practices in gifted education. Retrieved from http://education.wm.edu/centers/cfge/_documents/resources/articles/ongoingdilemma.pdf.

Vista, A., \& Grantham, T. (2009). Transferability of norms and its implication in cross-cultural gifted education: Norming Naglieri Nonverbal Ability Test (NNAT) in the Philippine public schools. Educ Res Policy Pract, 8, 111-121. http://link. springer.com/article/10.1007\%2Fs10671-009-9065-6\#/page-1.

Walters, H. (2009). Scientifically gifted. In B. Kerr (Ed.), Encyclopedia of giftedness, creativity, and talent (pp. 773-775). Thousand Oaks: Sage Publications.

Williams, B., Brown, T., \& Onsman, A. (2010). Exploratory factor analysis: A five-step guide for novices. J Emerg Primary Health Care, 8(3), 1-13.

Wong-Fernandez, B., \& Bustos-Orosa, A. (2007). Conceptions of giftedness among Tagalog-speaking Filipinos. In S. N. Phillipson \& M. McCann (Eds.), Conceptions of giftedness: Sociocultural perspectives (pp. 169-196). Mahwah: Lawrence Erlbaum Associates. 